\title{
Pricing Currency Option Based on the Extension Principle and Defuzzification via Weighting Parameter Identification
}

\author{
Jixiang Xu, ${ }^{1,2}$ Yanhua Tan, ${ }^{3}$ Jinggui Gao, ${ }^{4}$ and Enmin Feng ${ }^{1}$ \\ ${ }^{1}$ School of Mathematical Sciences, Dalian University of Technology, Dalian, Liaoning 116024, China \\ ${ }^{2}$ School of Sciences, Liaoning Shihua University, Fushun, Liaoning 113001, China \\ ${ }^{3}$ School of Sciences, Hebei University of Technology, Tianjin 300130, China \\ ${ }^{4}$ College of Information Science and Engineering, Shandong University of Science and Technology, Qingdao, Shandong 266510, China
}

Correspondence should be addressed to Jixiang Xu; jixiangxu@yahoo.cn

Received 24 November 2012; Accepted 20 January 2013

Academic Editor: Reinaldo Martinez Palhares

Copyright ( 2013 Jixiang Xu et al. This is an open access article distributed under the Creative Commons Attribution License, which permits unrestricted use, distribution, and reproduction in any medium, provided the original work is properly cited.

\begin{abstract}
We present a fuzzy version of the Garman-Kohlhagen (FG-K) formula for pricing European currency option based on the extension principle. In order to keep consistent with the real market, we assume that the interest rate, the spot exchange rate, and the volatility are fuzzy numbers in the FG-K formula. The conditions of a basic proposition about the fuzzy-valued functions of fuzzy subsets are modified. Based on the modified conditions and the extension principle, we prove that the fuzzy price obtained from the FG-K formula for European currency option is a fuzzy number. To simplify the trade, the weighted possibilistic mean (WPM) value with a weighting function is adopted to defuzzify the fuzzy price to a crisp price. The numerical example shows our method makes the $\alpha$-level set of fuzzy price smaller, which decreases the fuzziness. The example also indicates that the WPM value has different approximation effects to real market price by taking different values of weighting parameter in the weighting function. Inspired by this example, we provide a method, which can identify the optimal parameter.
\end{abstract}

\section{Introduction}

With the fast growing of the trading volume in the foreign exchange market, the trading of currency option has increased. It is well know that currency option manages the risk of the foreign exchange market. Hence, an appropriate formula for pricing currency option is becoming extremely significant. Garman and Kohlhagen (1983) [1] derived the closed-form formula (G-K formula) for pricing European currency option by the method of Black and Scholes (1973) [2]. There are six variables in the G-K formula, that is, the spot exchange rate, the volatility of spot exchange rate, the domestic and foreign risk-free interest rate, the strike price, and the time to maturity date. However, some variables in the $\mathrm{G}-\mathrm{K}$ formula are assumed as constants, which is inconsistent with the empirical phenomena, such as the volatility smile. According to these empirical phenomena, many researchers have been devoted to modify the G-K model, such as Chesney and Scott (1989) [3], Amin and Jarrow (1991) [4], Heston (1993) [5], Bates (1996) [6], Sarwar and Krehbiel (2000) [7], and Carr and $\mathrm{Wu}(2007)[8]$.

In general, the data, for instance, the spot exchange rate, the domestic or foreign risk-free interest rate, cannot be recorded or collected precisely. Usually, these financial tools may have different values in different commercial banks and financial institutions. Meanwhile, there are differences between the buy (bid) and the sale (ask) price for these financial tools, which are similar to bid-ask spreads in dealer markets for the stock. The existence of bid-ask spreads implies that we cannot precisely get the true market price. The bidask spreads are considered to be natural bands to represent the uncertainty around the market price, which is similar to fuzzy number. Furthermore, expert opinions or statistical estimators of market parameters may be expressed as fuzzy 
numbers. Therefore, the fuzzy set theory proposed by Zadeh (1965) [9] is useful to model such uncertainty. In a parallel development, the fuzzy set theory is applied to option pricing. Yoshida (2003) [10, 11] discussed the valuation of European call and put options in fuzzy environment. Muzzioli and Torricelli (2004) [12] discussed the pricing of European options in a multiperiod binomial model. Wu (2007) [13] obtained the fuzzy pattern of Black-Scholes formula using the extension principle. Xu et al. (2009) [14] and Zhang et al. (2012) [15] investigated a jump-diffusion option pricing model under fuzzy environment. Liu (2009) [16] applied fuzzy approach in [17] to the G-K formula of currency option. Xu et al. (2010) [18] and Guerra et al. (2011) [19] calculated the Greek letters of currency option and stock option under uncertainty environment, respectively, where the Greek letters are useful tools for managing option risk for an option writer. But the division operation of fuzzy numbers in Liu [16], Xu et al. [18] is invalid occasionally. In this paper, we adopt the extension principle to obtain the fuzzy version of $\mathrm{G}-\mathrm{K}$ formula for European currency option.

Owing to the vague of the currency market data as we just described above, some input variables, especially the interest rate, the spot exchange rate, and the volatility in the $\mathrm{G}-\mathrm{K}$ formula, cannot always be expected in a precise sense. Therefore, it is reasonable to assume these input variables in the G-K formula are fuzzy numbers. Then, the fuzzy version of the G-K formula for pricing European currency option is obtained via the extension principle. It is found that one of the conditions of the basic proposition in [13] is not verified. Actually, it is difficult to be verified. So we modify the conditions such that they can be satisfied easily. Based on the modified conditions and the extension principle, we prove that the fuzzy price obtained from the FG-K formula for European currency option is a fuzzy number. Meanwhile, we obtain the explicit expressions of the endpoints of every $\alpha$ level set (the closed interval) of the fuzzy price for European currency option. In so doing, the investor can pick any value from some closed interval ( $\alpha$-level set) of the fuzzy price with an acceptable belief degree $\alpha$ as European currency option trading price. To simplify the trade convenient, the weighted possibilistic mean (WPM) value with weighting function [20] is adopted to defuzzify the fuzzy price. Usually, the process of defuzzification is to find a crisp number that synthesizes the fuzzy price. Compared with the methods in $[16,18]$, the numerical example shows our method makes the $\alpha$-level set of fuzzy price smaller, which decreases the fuzziness. The reason of the differences is also discussed. The example also indicates that the WPM value has different approximation effects to real market price by taking different values of weighting parameter in the weighting function. Inspired by this example, we provide a method, which can identify the the optimal parameter.

The rest of the paper is organized as follows. In Section 2, some terminologies, notations of fuzzy number, and the main results of $[16,18]$ are introduced. The fundamental theories about the fuzzy-valued functions of fuzzy subsets are proposed in Section 3. In Section 4, the fuzzy version of the
G-K formula for European currency option is obtained by the extension principle. About the fuzzy price for European currency option, defuzzification via weighting parameter identification and numerical analysis are discussed in Section 5. Finally, the conclusions are stated in Section 6.

\section{Preliminaries}

In this section, we will introduce some definitions and propositions that will be used in the sequel. In order to weaken the conditions of the basic proposition in [13], we modify the definition of fuzzy number by another definitions of the 0-level set and the support set of fuzzy subset. Let $X$ be the universe of discourse. Throughout this paper, the universe set $X$ is assumed to be the set of all real number $(\mathbb{R})$ endowed with a usual topology.

Definition 1 (see [9]). A fuzzy subset $\widetilde{A}$ of $X$ is a set of ordered pairs $\widetilde{A}=\left\{\left(x, \mu_{\widetilde{A}}(x)\right) \mid x \in X\right\}$, where $\mu_{\widetilde{A}}: X \rightarrow[0,1]$ is called membership function of $\widetilde{A}$.

The concept of fuzzy subset was first introduced by [9]. The value $\mu_{\widetilde{A}}(x)$ can be interpreted as the membership degree of a point $x$ to the set $\widetilde{A}$.

Definition 2 (see [9]). A fuzzy subset $\widetilde{A}$ of $X$ is called normal if there exists at least one element $x \in X$ such that $\mu_{\widetilde{A}}(x)=1$.

Definition 3 (see [21]). Let $\widetilde{A}$ be a fuzzy subset of $X$. The support of $\widetilde{A}$, denoted by $\operatorname{Supp}(\widetilde{A})$, is the crisp set $\operatorname{cl}\{x \in X \mid$ $\left.\mu_{\widetilde{A}}(x)>0\right\}$.

Definition 4 (see [9]). Let $\widetilde{A}$ be a fuzzy subset of $X$. The $\alpha$-level set of $\widetilde{A}$, denoted by $\widetilde{A}_{\alpha}$, is the crisp set $\left\{x \in X \mid \mu_{\widetilde{A}}(x) \geq \alpha\right\}$, where $\alpha \in[0,1]$.

Definition 5 (see [9]). A fuzzy subset $\widetilde{A}$ of $X$ is called convex if for all $\alpha \in[0,1]$ its $\alpha$-level sets $\widetilde{A}_{\alpha}$ are (crisp) convex sets.

Alternatively, a fuzzy subset $\widetilde{A}$ of $X$ is a convex fuzzy subset if and only if $\mu_{\widetilde{A}}(\lambda x+(1-\lambda) y) \geq \min \left\{\mu_{\widetilde{A}}(x), \mu_{\widetilde{A}}(y)\right\}$ for all $\lambda \in[0,1]$; that is, $\mu_{\widetilde{A}}(x)$ is a quasi-concave function.

Definition 6 (see [22]). A real-valued function $f: \mathbb{R} \rightarrow$ $\mathbb{R}$ is called upper semicontinuous at a point $x \in \mathbb{R}$ if $f(x) \geq \lim \sup _{k \rightarrow \infty} f\left(x_{k}\right)$ for every sequence $\left\{x_{k}\right\} \subset \mathbb{R}$ that converges to $x$. If $f: \mathbb{R} \rightarrow \mathbb{R}$ is upper semicontinuous at every point in $\mathbb{R}$, we say that $f(x)$ is upper semicontinuous.

A real-valued function $f(x)$ is upper semicontinuous if and only if $\{x \mid f(x) \geq \alpha\}$ is closed for all $\alpha \in \mathbb{R}[22]$.

Definition 7 (fuzzy number). Let $\tilde{a}$ be a fuzzy subset of $\mathbb{R}$. Then $\tilde{a}$ is called a fuzzy number if the following conditions are satisfied:

(i) $\tilde{a}$ is a normal and convex fuzzy subset, 
(ii) its membership function $\mu_{\tilde{a}}(x)$ is upper semicontinuous,

(iii) the $\operatorname{Supp}(\widetilde{a})$ is bounded.

Note that if $\tilde{a}$ is a fuzzy number, then the $\alpha$-level set $\tilde{a}_{\alpha}$, for all $\alpha \in(0,1]$, is a compact (closed and bounded in $\mathbb{R}$ ) and convex set; that is, $\tilde{a}_{\alpha}$ is a bounded and closed interval for all $\alpha \in(0,1]$. Then, the $\alpha$-level set of $\tilde{a}$ is denoted as $\tilde{a}_{\alpha}=\left[\tilde{a}_{\alpha}^{L}, \tilde{a}_{\alpha}^{U}\right]$ for all $\alpha \in(0,1]$, and $\tilde{a}_{0}=\mathbb{R}$ especially. For convenience, we consider the fuzzy input variables as triangular fuzzy numbers; that is, the graph of the membership function looks like triangles.

Definition 8. A fuzzy number $\tilde{a} \in \mathscr{F}$ is a triangular fuzzy number if its membership function $\mu_{\tilde{a}}(x)$ is characterized as follows:

$$
\mu_{\tilde{a}}(x)= \begin{cases}\frac{x-a_{1}}{a_{2}-a_{1}} & a_{1} \leq x \leq a_{2}, \\ \frac{x-a_{3}}{a_{2}-a_{3}} & a_{2} \leq x \leq a_{3} \\ 0 & \text { otherwise. }\end{cases}
$$

Here, $\left[a_{1}, a_{3}\right]$ is the support set and the membership function has a peak at $a_{2}$. The triangular fuzzy number $\tilde{a}$ usually is denoted as $\tilde{a}=\left(a_{1}, a_{2}, a_{3}\right)$.

Definition 9 (see [20]). Let $\tilde{a} \in \mathscr{F}$ be a fuzzy number with $\tilde{a}_{\alpha}=\left[\widetilde{a}_{\alpha}^{L}, \tilde{a}_{\alpha}^{U}\right], \alpha \in[0,1]$. A function $f:[0,1] \rightarrow \mathbb{R}$ is said to be a weighting function if $f(x)$ is nonnegative, monotone increasing and satisfies the normalization condition:

$$
\int_{0}^{1} f(\alpha) \mathrm{d} \alpha=1
$$

We define the $f$-weighted possibilistic mean (WPM) value of the fuzzy number $\tilde{a}$ as

$$
\bar{M}_{f}(\widetilde{a})=\int_{0}^{1} \frac{\tilde{a}_{\alpha}^{L}+\tilde{a}_{\alpha}^{U}}{2} f(\alpha) \mathrm{d} \alpha .
$$

Next, the decomposition theory is introduced which establishes an important connection between fuzzy sets and crisp sets. That is, we can get the expression of membership function of a fuzzy set if all its $\alpha$-level sets are available.

Proposition 10 (decomposition theorem [23-25]). Let $\widetilde{A}$ be a fuzzy subset with membership function $\mu_{\widetilde{A}}(x)$ and $\alpha$-level set $\widetilde{A}_{\alpha}=\left\{x \mid \mu_{\widetilde{A}}(x) \geq \alpha\right\}$. Then

$$
\mu_{\widetilde{A}}(x)=\sup _{0 \leq \alpha \leq 1} \alpha \cdot 1_{\widetilde{A}_{\alpha}}(x),
$$

where $1_{\widetilde{A}_{\alpha}}(x)$ is an indicator function of set $\widetilde{A}_{\alpha}$, that is, $1_{\widetilde{A}_{\alpha}}(x)=1$ if $x \in \widetilde{A}_{\alpha}$ and $1_{\widetilde{A}_{\alpha}}(x)=0$ if $x \notin \widetilde{A}_{\alpha}$.

Let $\mathscr{F}$ denote all the fuzzy subsets of $\mathbb{R}$. Assume $\widetilde{A}_{i} \in \mathscr{F}$, $i=1,2, \ldots, n$. Let $\widetilde{A} \triangleq \widetilde{A}_{1} \times \widetilde{A}_{2} \times \cdots \times \widetilde{A}_{n}$ and $\operatorname{Supp}(\widetilde{A}) \triangleq$ $\operatorname{Supp}\left(\widetilde{A}_{1}\right) \times \operatorname{Supp}\left(\widetilde{A}_{2}\right) \times \cdots \times \operatorname{Supp}\left(\widetilde{A}_{n}\right)$, where $\times$ is Cartesian product. A fruitful and powerful tool of fuzzy set theory for calculating the fuzzy-valued functions on fuzzy sets is the extension principle.

Proposition 11 (extension principle [23-25]). Let $f: \mathbb{R}^{n} \rightarrow$ $\mathbb{R}$ be a real-valued function and let $\widetilde{A}_{1}, \widetilde{A}_{2}, \ldots, \widetilde{A}_{n}$ be fuzzy subsets of $\mathbb{R}$. Then one can induce a fuzzy-valued function $\tilde{f}: \mathscr{F}^{n} \rightarrow \mathscr{F}$ according to the real-valued function $f\left(x_{1}, x_{2}, \ldots, x_{n}\right)$. In fact, $\widetilde{f}\left(\widetilde{A}_{1}, \widetilde{A}_{2}, \ldots, \widetilde{A}_{n}\right)$ is a fuzzy subset of $\mathbb{R}$. Then the membership function of $\widetilde{f}\left(\widetilde{A}_{1}, \widetilde{A}_{2}, \ldots, \widetilde{A}_{n}\right)$ is characterized as follows:

$$
\begin{aligned}
& \mu_{\tilde{f}\left(\widetilde{A}_{1}, \widetilde{A}_{2}, \ldots, \widetilde{A}_{n}\right)}(r) \\
& \quad=\sup _{\left\{\left(x_{1}, \ldots, x_{n}\right) \mid r=f\left(x_{1}, \ldots, x_{n}\right)\right\} \cap \operatorname{Supp}(\widetilde{A})} \min _{1 \leq i \leq n}\left\{\mu_{\widetilde{A}_{i}}\left(x_{i}\right)\right\},
\end{aligned}
$$

where $\sup _{x \in \emptyset} g(x)=0$.

Remark 12. It is necessary to point out that there is a term $\operatorname{Supp}(\widetilde{A})$ in (5), which does not exist in [23-25]. Since $\sup _{x \in \emptyset} g(x)=0$, the term $\operatorname{Supp}(\widetilde{A})$ does not affect the proposition. However, it plays an important role in our results.

Proposition 13 (see [22]). Let $S$ be a nonempty compact set in $\mathbb{R}^{n}$. If $f$ is upper semicontinuous on $S$, then $f$ attains maximum over $S$ and if $f$ is lower semicontinuous on $S$, then $f$ attains minimum over $S$.

Proposition 14. (i) [26, Theorem 4.25] Let $f: S \rightarrow T$ be a function from one metric space $\left(S, d_{S}\right)$ to another $\left(T, d_{T}\right)$. If $f$ is continuous on a compact subset $X$ of $S$, then the image $f(X)$ is a compact subset of $T$; in particular, $f(X)$ is a closed and bounded in $T$.

(ii) [26, Theorem 4.37] Let $f: S \rightarrow T$ be a function from one metric space $\left(S, d_{S}\right)$ to another $\left(T, d_{T}\right)$. Let $X$ be a connected subset of S. If $f$ is continuous on $X$, then the $f(X)$ is a connected subset of $T$.

We also review the results in $[16,18]$ about the formula for currency option under uncertain environment as follows:

$$
\begin{aligned}
\left(\widetilde{C}_{t}\right)_{\alpha}^{L}= & \left(\widetilde{Q}_{t}\right)_{\alpha}^{L} \cdot e^{-\left(\widetilde{r}_{f}\right)_{\alpha}^{U} \times(T-t)} \cdot N\left(\left(\widetilde{d}_{1}\right)_{\alpha}^{L}\right) \\
& -K \cdot e^{-\left(\widetilde{r}_{d}\right)_{\alpha}^{L} \times(T-t)} \cdot N\left(\left(\widetilde{d}_{2}\right)_{\alpha}^{U}\right), \\
\left(\widetilde{C}_{t}\right)_{\alpha}^{U}= & \left(\widetilde{Q}_{t}\right)_{\alpha}^{U} \cdot e^{-\left(\widetilde{r}_{f}\right)_{\alpha}^{L} \times(T-t)} \cdot N\left(\left(\widetilde{d}_{1}\right)_{\alpha}^{U}\right) \\
& -K \cdot e^{-\left(\widetilde{r}_{d}\right)_{\alpha}^{U} \times(T-t)} \cdot N\left(\left(\widetilde{d}_{2}\right)_{\alpha}^{L}\right),
\end{aligned}
$$


where

$$
\begin{aligned}
& \left(\widetilde{d}_{1}\right)_{\alpha}^{L}=\left(\ln \left(\frac{\left(\widetilde{Q}_{t}\right)_{\alpha}^{L}}{K}\right)\right. \\
& +\left[\left(\widetilde{r}_{d}\right)_{\alpha}^{L}-\left(\widetilde{r}_{f}\right)_{\alpha}^{U}+\frac{1}{2}\left(\left(\widetilde{\sigma}_{\mathrm{Q}}\right)_{\alpha}^{L}\right)^{2}\right] \\
& \times(T-t))\left(\left(\widetilde{\sigma}_{\mathrm{Q}}\right)_{\alpha}^{U} \sqrt{T-t}\right)^{-1} \\
& \left(\widetilde{d}_{1}\right)_{\alpha}^{U}=\left(\ln \left(\frac{\left(\widetilde{Q}_{t}\right)_{\alpha}^{U}}{K}\right)\right. \\
& +\left[\left(\widetilde{r}_{d}\right)_{\alpha}^{U}-\left(\widetilde{r}_{f}\right)_{\alpha}^{L}+\frac{1}{2}\left(\left(\widetilde{\sigma}_{\mathrm{Q}}\right)_{\alpha}^{U}\right)^{2}\right] \\
& \times(T-t))\left(\left(\widetilde{\sigma}_{\mathrm{Q}}\right)_{\alpha}^{L} \sqrt{T-t}\right)^{-1}, \\
& \left(\widetilde{d}_{2}\right)_{\alpha}^{L}=\left(\widetilde{d}_{1}\right)_{\alpha}^{L}-\left(\widetilde{\sigma}_{\mathrm{Q}}\right)_{\alpha}^{U} \sqrt{T-t}, \\
& \left(\tilde{d}_{2}\right)_{\alpha}^{U}=\left(\widetilde{d}_{1}\right)_{\alpha}^{U}-\left(\widetilde{\sigma}_{Q}\right)_{\alpha}^{L} \sqrt{T-t} .
\end{aligned}
$$

\section{Expressing of $\alpha$-Level Set of the Fuzzy-Valued Functions of Fuzzy Numbers}

In this section, we will establish the fundamental proposition for this paper, which based on the decomposition theorem, the extension principle, and some properties about continuous function. The following proposition is a result about the fuzzy-valued functions of fuzzy subsets.

Proposition 15. Let $f: \mathbb{R}^{n} \rightarrow \mathbb{R}$ be a continuous, surjective, real-valued function and let $\widetilde{A}_{1}, \widetilde{A}_{2}, \ldots, \widetilde{A}_{n}$ be fuzzy subsets of $\mathbb{R}$. Let $\widetilde{f}: \mathscr{F}^{n} \rightarrow \mathscr{F}$ be a fuzzy-valued function induced by $f\left(x_{1}, x_{2}, \ldots, x_{n}\right)$ via the extension principle defined in (5). Suppose that

(i) $\mu_{\widetilde{A}_{i}}\left(x_{i}\right)$ is upper semicontinuous on $\mathbb{R}, i=1,2, \ldots, n$,

(ii) $\operatorname{Supp}(\mathbb{A})$ is a bounded set of $\mathbb{R}^{n}$, then

(a) $\left(\tilde{f}\left(\widetilde{A}_{1}, \widetilde{A}_{2}, \ldots, \widetilde{A}_{n}\right)\right)_{\alpha}$

$$
\begin{gathered}
=\left\{f\left(x_{1}, x_{2}, \ldots, x_{n}\right) \mid x_{1} \in\left(\widetilde{A}_{1}\right)_{\alpha},\right. \\
\left.x_{2} \in\left(\widetilde{A}_{2}\right)_{\alpha}, \ldots, x_{n} \in\left(\widetilde{A}_{n}\right)_{\alpha}\right\},
\end{gathered}
$$

$\forall \alpha \in[0,1]$,

(b) $\operatorname{Supp}\left(\widetilde{f}\left(\widetilde{A}_{1}, \widetilde{A}_{2}, \ldots, \widetilde{A}_{n}\right)\right)$

$$
\begin{aligned}
=\{f & \left(x_{1}, x_{2}, \ldots, x_{n}\right) \mid x_{1} \in \operatorname{Supp}\left(\widetilde{A}_{1}\right), \\
& \left.x_{2} \in \operatorname{Supp}\left(\widetilde{A}_{2}\right), \ldots, x_{n} \in \operatorname{Supp}\left(\widetilde{A}_{n}\right)\right\} .
\end{aligned}
$$

Proof. (a) For $\alpha=0$, (8) holds from Definition 4 and the property of surjection of $f\left(x_{1}, x_{2}, \ldots, x_{n}\right)$.

For $\alpha \in(0,1]$, let $r \in\left\{f\left(x_{1}, x_{2}, \ldots, x_{n}\right) \mid x_{1} \in\left(\widetilde{A}_{1}\right)_{\alpha}, x_{2} \in\right.$ $\left.\left(\widetilde{A}_{2}\right)_{\alpha}, \ldots, x_{n} \in\left(\widetilde{A}_{n}\right)_{\alpha}\right\}$. Then there exists $\left(x_{1}^{*}, x_{2}^{*}, \ldots, x_{n}^{*}\right) \in$ $\left(\widetilde{A}_{1}\right)_{\alpha} \times\left(\widetilde{A}_{2}\right)_{\alpha} \times \cdots \times\left(\widetilde{A}_{n}\right)_{\alpha}$ such that $r=f\left(x_{1}^{*}, x_{2}^{*}, \ldots, x_{n}^{*}\right)$. Thus $\min _{1 \leq i \leq n}\left\{\mu_{\widetilde{A}_{i}}\left(x_{i}^{*}\right)\right\} \geq \alpha$. It follows that

$$
\begin{aligned}
& \mu_{\tilde{f}\left(\widetilde{A}_{1}, \widetilde{A}_{2}, \ldots, \widetilde{A}_{n}\right)}(r) \\
& \quad=\sup _{\left\{\left(x_{1}, \ldots, x_{n}\right) \mid r=f\left(x_{1}, \ldots, x_{n}\right)\right\} \cap \operatorname{Supp}(\widetilde{A})} \min _{1 \leq i \leq n}\left\{\mu_{\widetilde{A}_{i}}\left(x_{i}\right)\right\} \geq \alpha,
\end{aligned}
$$

which means that

$$
\begin{aligned}
& \left\{f\left(x_{1}, x_{2}, \ldots, x_{n}\right) \mid x_{1} \in\left(\widetilde{A}_{1}\right)_{\alpha}\right. \\
& \left.\quad x_{2} \in\left(\widetilde{A}_{2}\right)_{\alpha}, \ldots, x_{n} \in\left(\widetilde{A}_{n}\right)_{\alpha}\right\} \subset\left(\widetilde{f}\left(\widetilde{A}_{1}, \widetilde{A}_{2}, \ldots, \widetilde{A}_{n}\right)\right)_{\alpha} .
\end{aligned}
$$

On the other hand, $\mu_{\widetilde{A}_{i}}\left(x_{i}\right)$ is upper semicontinuous on $\mathbb{R}$, then $U_{i}=\left\{x_{i} \mid \mu_{\widetilde{A}_{i}}\left(x_{i}\right) \geq \alpha\right\}$ is a closed subset of $\mathbb{R}, i=$ $1,2, \ldots, n$. Therefore, $C_{i}=\underbrace{\mathbb{R} \times \cdots \times \mathbb{R}} \times U_{i} \times \underbrace{\mathbb{R} \times \cdots \times \mathbb{R}}$ is a closed subset of $\mathbb{R}^{n} i=1,2, \ldots, n$. Since

$$
\begin{aligned}
& \left\{\left(x_{1}, x_{2}, \ldots, x_{n}\right) \mid \min _{1 \leq i \leq n}\left\{\mu_{\widetilde{A}_{i}}\left(x_{i}\right)\right\} \geq \alpha\right\} \\
& \quad=\left\{\left(x_{1}, x_{2}, \ldots, x_{n}\right) \mid \mu_{\widetilde{A}_{i}}\left(x_{i}\right) \geq \alpha, i=1,2, \ldots, n\right\} \\
& \quad=\bigcap_{i=1}^{n} C_{i}
\end{aligned}
$$

is a closed subset of $\mathbb{R}^{n}$, we have $\min _{1 \leq i \leq n}\left\{\mu_{\widetilde{A}_{i}}\left(x_{i}\right)\right\}$ is upper semicontinuous on $\mathbb{R}^{n}$. Let $r \in\left(\widetilde{f}\left(\widetilde{A}_{1}, \widetilde{A}_{2}, \ldots, \widetilde{A}_{n}\right)\right)_{\alpha}$, that is,

$$
\sup _{\left\{\left(x_{1}, \ldots, x_{n}\right) \mid r=f\left(x_{1}, \ldots, x_{n}\right)\right\} \cap \operatorname{Supp}(\widetilde{A})} \min _{1 \leq i \leq n}\left\{\mu_{\widetilde{A}_{i}}\left(x_{i}\right)\right\} \geq \alpha .
$$

Since $\left\{\left(x_{1}, \ldots, x_{n}\right) \quad \mid r=f\left(x_{1}, \ldots, x_{n}\right)\right\}$ is a closed subset of $\mathbb{R}^{n}$ and $\operatorname{Supp}(\widetilde{A})$ is a compact set of $\mathbb{R}^{n}$ and $\min _{1 \leq i \leq n}\left\{\mu_{\widetilde{A}_{i}}\left(x_{i}\right)\right\}$ is upper semicontinuous on $\mathbb{R}^{n}$, we conclude from Proposition 13 that there exists $\left(\bar{x}_{1}, \bar{x}_{2}, \ldots, \bar{x}_{n}\right)$ such that $r=f\left(\bar{x}_{1}, \bar{x}_{2}, \ldots, \bar{x}_{n}\right)$ and $\min _{1 \leq i \leq n}\left\{\mu_{\widetilde{A}_{i}}\left(\bar{x}_{i}\right)\right\} \geq \alpha$. Therefore $\mu_{\widetilde{A}_{i}}\left(\bar{x}_{i}\right) \geq \alpha$, that is, $\bar{x}_{i} \in\left(\widetilde{A}_{i}\right)_{\alpha}, i=1,2, \ldots, n$. This means

$$
\begin{array}{r}
r \in\left\{f\left(x_{1}, x_{2}, \ldots, x_{n}\right) \mid x_{1} \in\left(\widetilde{A}_{1}\right)_{\alpha},\right. \\
\left.x_{2} \in\left(\widetilde{A}_{2}\right)_{\alpha}, \ldots, x_{n} \in\left(\widetilde{A}_{n}\right)_{\alpha}\right\} .
\end{array}
$$

Therefore,

$$
\begin{array}{r}
\left(\widetilde{f}\left(\widetilde{A}_{1}, \widetilde{A}_{2}, \ldots, \widetilde{A}_{n}\right)\right)_{\alpha} \subset\left\{f\left(x_{1}, x_{2}, \ldots, x_{n}\right) \mid x_{1} \in\left(\widetilde{A}_{1}\right)_{\alpha},\right. \\
\left.x_{2} \in\left(\widetilde{A}_{2}\right)_{\alpha}, \ldots, x_{n} \in\left(\widetilde{A}_{n}\right)_{\alpha}\right\}
\end{array}
$$

which completes the proof of (a). 
(b) Let $r \in \operatorname{Supp}\left(\widetilde{f}\left(\widetilde{A}_{1}, \widetilde{A}_{2}, \ldots, \widetilde{A}_{n}\right)\right)$, we conclude from Definition 3 that there exists a sequence $\left\{r_{m}\right\}_{m=1}^{\infty}$ which satisfies $r_{m} \rightarrow r$ and $\mu_{\tilde{f}\left(\widetilde{A}_{1}, \widetilde{A}_{2}, \ldots, \widetilde{A}_{n}\right)}\left(r_{m}\right)>0$, that is,

$$
\sup _{\left\{\left(x_{1}, \ldots, x_{n}\right) \mid r_{m}=f\left(x_{1}, \ldots, x_{n}\right)\right\} \cap \operatorname{Supp}(\widetilde{A})} \min _{1 \leq i \leq n}\left\{\mu_{\widetilde{A}_{i}}\left(x_{i}\right)\right\}>0 .
$$

Since $\left\{\left(x_{1}, \ldots, x_{n}\right) \quad \mid \quad r_{m}=f\left(x_{1}, \ldots, x_{n}\right)\right\}$ is closed and $\operatorname{Supp}(\widetilde{A})$ is bounded and closed, then $\left\{\left(x_{1}, \ldots, x_{n}\right)\right.$ । $\left.r_{m}=f\left(x_{1}, \ldots, x_{n}\right)\right\} \cap \operatorname{Supp}(\widetilde{A})$ is compact. Moreover, we deduce that $\min _{1 \leq i \leq n}\left\{\mu_{\widetilde{A}_{i}}\left(x_{i}\right)\right\}$ is upper semicontinuous on $\mathbb{R}^{n}$ according to the proof of (a). Consequently, we conclude from Proposition 13 that there exist $\left\{\bar{x}_{1}^{m}\right\}_{m=1}^{\infty},\left\{\bar{x}_{2}^{m}\right\}_{m=1}^{\infty}, \ldots,\left\{\bar{x}_{n}^{m}\right\}_{m=1}^{\infty}$ such that

$$
\begin{aligned}
& \mu_{\tilde{f}\left(\widetilde{A}_{1}, \widetilde{A}_{2}, \ldots, \widetilde{A}_{n}\right)}\left(r_{m}\right) \\
& \quad=\min _{1 \leq i \leq n}\left\{\mu_{\widetilde{A}_{i}}\left(\bar{x}_{i}^{m}\right)\right\}>0 \quad \text { for } m \in \mathrm{N}, i=1,2, \ldots, n,
\end{aligned}
$$

where $r_{m}=f\left(\bar{x}_{1}^{m}, \ldots, \bar{x}_{n}^{m}\right)$ and $\bar{x}_{i}^{m} \in \operatorname{Supp}\left(\widetilde{A}_{i}\right)$. Since $\operatorname{Supp}(\widetilde{A}) \cap\left\{\left(x_{1}, \ldots, x_{n}\right) \mid r_{m}=f\left(x_{1}, \ldots, x_{n}\right)\right\}$ is compact, for each $i \in\{1,2, \ldots, n\}$, there exists a subsequence $\left\{\bar{x}_{i}^{m_{k}}\right\}_{k=1}^{\infty}$ of $\left\{\bar{x}_{i}^{m}\right\}_{m=1}^{\infty}$ such that $\bar{x}_{i}^{m_{k}} \rightarrow \bar{x}_{i} \in \operatorname{Supp}\left(\widetilde{A}_{i}\right)$ as $k \rightarrow \infty$. Notice that

$$
\begin{aligned}
r_{m_{k}}= & f\left(\bar{x}_{1}^{m_{k}}, \ldots, \bar{x}_{n}^{m_{k}}\right) \longrightarrow r \\
& f\left(\bar{x}_{1}^{m_{k}}, \ldots, \bar{x}_{n}^{m_{k}}\right) \longrightarrow f\left(\bar{x}_{1}, \ldots, \bar{x}_{n}\right) \quad \text { as } k \longrightarrow \infty .
\end{aligned}
$$

We have $r=f\left(\bar{x}_{1}, \ldots, \bar{x}_{n}\right)$, where $\bar{x}_{i} \in \operatorname{Supp}\left(\widetilde{A}_{i}\right)$. Then

$$
\begin{gathered}
\operatorname{Supp}\left(\widetilde{f}\left(\widetilde{A}_{1}, \widetilde{A}_{2}, \ldots, \widetilde{A}_{n}\right)\right) \\
\subset\left\{f\left(x_{1}, x_{2}, \ldots, x_{n}\right) \mid x_{1} \in \operatorname{Supp}\left(\widetilde{A}_{1}\right), \ldots,\right. \\
\left.x_{n} \in \operatorname{Supp}\left(\widetilde{A}_{n}\right)\right\} .
\end{gathered}
$$

For the converse, let $z \in\left\{f\left(x_{1}, x_{2}, \ldots, x_{n}\right) \quad \mid \quad x_{1} \in\right.$ $\left.\operatorname{Supp}\left(\widetilde{A}_{1}\right), \ldots, x_{n} \in \operatorname{Supp}\left(\widetilde{A}_{n}\right)\right\}$. Then there exist sequences $\left\{x_{i}^{m}\right\}_{m=1}^{\infty}, i=1,2, \ldots, n$, which satisfy $\mu_{\widetilde{A}_{i}}\left(x_{i}^{m}\right)>0$ and $x_{i}^{m} \rightarrow x_{i}$ as $m \rightarrow \infty$, where $x_{i} \in \operatorname{Supp}\left(\widetilde{A}_{i}\right)$ and $z=$ $f\left(x_{1}, x_{2}, \ldots, x_{n}\right)$. Recall the continuity of $f\left(x_{1}, x_{2}, \ldots, x_{n}\right)$, we have

$$
\begin{aligned}
& \left\{f\left(x_{1}, x_{2}, \ldots, x_{n}\right) \mid x_{1} \in \operatorname{Supp}\left(\widetilde{A}_{1}\right), \ldots, x_{n} \in \operatorname{Supp}\left(\widetilde{A}_{n}\right)\right\} \\
& \quad \quad \operatorname{Supp}\left(\widetilde{f}\left(\widetilde{A}_{1}, \widetilde{A}_{2}, \ldots, \widetilde{A}_{n}\right)\right) .
\end{aligned}
$$

This completes the proof.

Remark 16. One of the conditions of Proposition in [13] is that $\left\{\left(x_{1}, \ldots, x_{n}\right) \mid r=f\left(x_{1}, \ldots, x_{n}\right)\right\}$ is compact for all $r \in$ Range $(f)$. This one is not verified there. Actually, it is difficult to be verified. Meanwhile, (8) only holds for $\alpha \in(0,1]$. We change the above conditions to (i) $\mu_{\widetilde{A}_{i}}\left(x_{i}\right)$ is upper semicontinuous on $\mathbb{R}, i=1,2, \ldots, n$; (ii) $\operatorname{Supp}(\widetilde{A})$ is bounded of $\mathbb{R}^{n}$ and; (iii) $f: \mathbb{R}^{n} \rightarrow \mathbb{R}$ is a continuous, surjective, realvalued function. Conditions (i)-(iii) can be easily satisfied. At the same time, (8) holds for $\alpha \in[0,1]$ and (9) is also obtained.

The following is the fundamental proposition for discussing the Garman-Kohlhagen formula for European currency option via the extension principle.

Proposition 17. Let $f: \mathbb{R}^{n} \rightarrow \mathbb{R}$ be a continuous, surjective, real-valued function and let $\widetilde{a}_{1}, \widetilde{a}_{2}, \ldots, \widetilde{a}_{n}$ be fuzzy numbers. Let $\tilde{f}: \mathscr{F}^{n} \rightarrow \mathscr{F}$ be a fuzzy-valued function induced by $f\left(x_{1}, x_{2}, \ldots, x_{n}\right)$ via the extension principle defined in (5). Then $\tilde{f}\left(\widetilde{a}_{1}, \tilde{a}_{2}, \ldots, \widetilde{a}_{n}\right)$ is a fuzzy number and its $\alpha$-level set is

$$
\begin{aligned}
& \left(\tilde{f}\left(\widetilde{a}_{1}, \tilde{a}_{2}, \ldots, \tilde{a}_{n}\right)\right)_{\alpha} \\
& =\left\{f\left(x_{1}, x_{2}, \ldots, x_{n}\right) \mid x_{1} \in\left(\widetilde{a}_{1}\right)_{\alpha},\right. \\
& \left.\quad x_{2} \in\left(\widetilde{a}_{2}\right)_{\alpha}, \ldots, x_{n} \in\left(\widetilde{a}_{n}\right)_{\alpha}\right\} \\
& =\left\{f\left(x_{1}, x_{2}, \ldots, x_{n}\right) \mid\left(\widetilde{a}_{1}\right)_{\alpha}^{L} \leq x_{1} \leq\left(\widetilde{a}_{1}\right)_{\alpha}^{U}, \ldots,\left(\widetilde{a}_{n}\right)_{\alpha}^{L}\right. \\
& \left.\leq x_{n} \leq\left(\widetilde{a}_{n}\right)_{\alpha}^{U}\right\} .
\end{aligned}
$$

Proof. Let $X_{\alpha} \triangleq\left\{\left(x_{1}, x_{2}, \ldots, x_{n}\right) \quad \mid x_{1} \in\left(\widetilde{a}_{1}\right)_{\alpha}, x_{2} \in\right.$ $\left.\left(\tilde{a}_{2}\right)_{\alpha}, \ldots, x_{n} \in\left(\tilde{a}_{n}\right)_{\alpha}\right\}$ for all $\alpha \in(0,1]$. Then it follows from Definition 7 that $X_{\alpha}$ is an $n$-dimensional bounded interval; that is, $X_{\alpha}$ is a compact and connected subset of $\mathbb{R}^{n}$. Next, we conclude from Propositions 15 and 14 that

(i) $\left\{\mu_{\tilde{f}\left(\tilde{a}_{1}, \tilde{a}_{2}, \ldots, \tilde{a}_{n}\right)} \geq \alpha\right\}=\left(\tilde{f}\left(\widetilde{a}_{1}, \tilde{a}_{2}, \ldots, \tilde{a}_{n}\right)\right)_{\alpha}=\left\{f\left(x_{1}, x_{2}\right.\right.$, $\left.\left.\ldots, x_{n}\right) \mid\left(x_{1}, x_{2}, \ldots, x_{n}\right) \in X_{\alpha}\right\}$ is a compact and connected subset of $\mathbb{R}$ for all $\alpha \in(0,1]$;

(ii) $\left(\tilde{f}\left(\widetilde{a}_{1}, \widetilde{a}_{2}, \ldots, \widetilde{a}_{n}\right)\right)_{0}=\mathbb{R}$ is closed and convex set;

(iii) $\operatorname{Supp}\left(\tilde{f}\left(\widetilde{a}_{1}, \tilde{a}_{2}, \ldots, \tilde{a}_{n}\right)\right)=\left\{f\left(x_{1}, x_{2}, \ldots, x_{n}\right) \mid x_{1} \in\right.$ $\left.\operatorname{Supp}\left(\widetilde{a}_{1}\right), x_{2} \in \operatorname{Supp}\left(\widetilde{a}_{2}\right), \ldots, x_{n} \in \operatorname{Supp}\left(\widetilde{a}_{n}\right)\right\}$.

Furthermore,

$\left(i^{\prime}\right)$ the membership function $\mu_{\tilde{f}}\left(\widetilde{a}_{1}, \tilde{a}_{2}, \ldots, \tilde{a}_{n}\right)$ of $\tilde{f}\left(\widetilde{a}_{1}, \tilde{a}_{2}\right.$, $\left.\ldots, \widetilde{a}_{n}\right)$ is upper semicontinuous;

(ii') $\tilde{f}\left(\widetilde{a}_{1}, \widetilde{a}_{2}, \ldots, \widetilde{a}_{n}\right)$ is a convex fuzzy subset;

(iii') $\operatorname{Supp}\left(\tilde{f}\left(\widetilde{a}_{1}, \widetilde{a}_{2}, \ldots, \widetilde{a}_{n}\right)\right)$ is bounded.

Obviously, $\tilde{f}\left(\widetilde{a}_{1}, \tilde{a}_{2}, \ldots, \widetilde{a}_{n}\right)$ is a normal fuzzy subset, as $X_{1}$ is nonempty. Therefore, from Definition 7 we conclude that $\tilde{f}\left(\widetilde{a}_{1}, \tilde{a}_{2}, \ldots, \widetilde{a}_{n}\right)$ is a fuzzy number and its $\alpha$-level set is (21). This completes the proof.

\section{Fuzzy Currency Options Pricing Formula via the Extension Principle}

4.1. The G-K Formula for European Currency Option. The closed-form solution for European currency option pricing formula has been derived by Garman and Kohlhagen [1]. The G-K formula for European call currency option with the 
expiry date $T$ and the strike price $K$ is described as follows. Let $Q_{t}, C_{t}$ denote the spot exchange rate, and the price of European call currency option at time $t \in[0, T]$, respectively, then

$$
C_{t}=Q_{t} \cdot e^{-r_{f} \tau} \cdot N\left(d_{1}\right)-K \cdot e^{-r_{d} \tau} \cdot N\left(d_{2}\right),
$$

where $\tau=T-t, d_{1}=\left[\ln \left(Q_{t} / K\right)+\left(r_{d}-r_{f}+(1 / 2) \sigma_{Q}^{2}\right) \tau\right] /\left(\sigma_{Q} \sqrt{\tau}\right)$, $d_{2}=d_{1}-\sigma_{\mathrm{Q}} \sqrt{\tau}, r_{f}, r_{d}, \sigma_{\mathrm{Q}}, N(\cdot)$ denote the foreign interest rate, the domestic interest rate, the volatility of spot exchange rate and the standard Gaussian cumulative distribution function, respectively. Let

$$
f\left(q, t, K, r_{d}, r_{f}, \sigma\right)=q \cdot e^{-r_{f} t} \cdot N\left(d_{1}\right)-K \cdot e^{-r_{d} t} \cdot N\left(d_{2}\right),
$$

then

$$
C_{t}=f\left(Q_{t}, T-t, K, r_{d}, r_{f}, \sigma_{Q}\right),
$$

for all $t \in[0, T]$. Furthermore, the price $P_{t}$ of European put option at time $t \in[0, T]$ with same expiry date $T$ and strike price $K$ can be obtained by the following put-call parity relationship (Musiela and Rutkowski [27]):

$$
C_{t}-P_{t}=e^{-r_{f}(T-t)} \cdot Q_{t}-e^{-r_{d}(T-t)} \cdot K .
$$

Let

$$
\begin{aligned}
& g\left(q, t, K, r_{d}, r_{f}, \sigma\right) \\
& \quad=f\left(q, t, K, r_{d}, r_{f}, \sigma\right)-e^{-r_{f} t} \cdot q+e^{-r_{d} t} \cdot K
\end{aligned}
$$

for all $t \in[0, T]$, then

$$
P_{t}=g\left(Q_{t}, T-t, K, r_{d}, r_{f}, \sigma_{Q}\right) .
$$

4.2. The Fuzzy Version of the G-K Formula for European Currency Option. As the discussion in Section 1, it is suitable to represent the four input variables in the G-K formula by fuzzy numbers. Thus, we give the following assumptions.

\section{Assumption 1.}

(i) The spot exchange rate at time $t \in[0, T]$ is fuzzy number $\widetilde{Q}_{t}$;

(ii) the domestic interest rate is fuzzy number $\widetilde{r}_{d}$;

(iii) the foreign interest rate is fuzzy number $\widetilde{r}_{f}$;

(iv) the volatility of spot exchange rate is fuzzy number $\tilde{\sigma}_{Q}$.

Based on Assumption 1, (24) and the extension principle (Proposition 11), the original price for European call currency option $C_{t}$ at time $t \in[0, T]$ turns into fuzzy subset $\widetilde{C}_{t} \in \mathscr{F}$ with the membership function

$$
\begin{aligned}
\mu_{\widetilde{C}_{t}}(c)= & \sup _{\left\{\left(q, r_{d}, r_{f}, \sigma_{Q}\right) \mid c=f\left(q, T-t, K, r_{d}, r_{f}, \sigma_{\mathrm{Q}}\right)\right\} \cap \operatorname{Supp}(\widetilde{A})} \\
& \quad \times \min \left\{\mu_{\widetilde{Q}_{t}}(q), \mu_{\widetilde{r}_{d}}\left(r_{d}\right), \mu_{\widetilde{r}_{f}}\left(r_{f}\right), \mu_{\widetilde{\sigma}_{\mathrm{Q}}}\left(\sigma_{\mathrm{Q}}\right)\right\},
\end{aligned}
$$

where $\operatorname{Supp}(\widetilde{A})=\operatorname{Supp}\left(\widetilde{Q}_{t}\right) \times \operatorname{Supp}\left(\widetilde{r}_{d}\right) \times \operatorname{Supp}\left(\widetilde{r}_{f}\right) \times \operatorname{Supp}\left(\widetilde{\sigma}_{Q}\right)$. Since the function $f\left(Q_{t}, T-t, K, r_{d}, r_{f}, \sigma_{Q}\right)$ satisfies conditions of Proposition 17, we conclude that the fuzzy price $\widetilde{C}_{t}$ at time $t \in[0, T]$ is a fuzzy number. Furthermore, its $\alpha$-level set $\left(\widetilde{C}_{t}\right)_{\alpha}$ is

$$
\begin{array}{r}
\left(\widetilde{C}_{t}\right)_{\alpha}=\left\{f\left(q, T-t, K, r_{d}, r_{f}, \sigma_{\mathrm{Q}}\right) \mid q \in\left(\widetilde{Q}_{t}\right)_{\alpha},\right. \\
\left.r_{d} \in\left(\widetilde{r}_{d}\right)_{\alpha}, r_{f} \in\left(\widetilde{r}_{f}\right)_{\alpha}, \sigma_{\mathrm{Q}} \in\left(\widetilde{\sigma}_{\mathrm{Q}}\right)_{\alpha}\right\},
\end{array}
$$

for all $\alpha \in[0,1]$. On the other hand, from Definition 7 , the $\alpha$-level set $\left(\widetilde{C}_{t}\right)_{\alpha}$ of $\widetilde{C}_{t}$ is a closed interval

$$
\left(\widetilde{C}_{t}\right)_{\alpha}=\left[\left(\widetilde{C}_{t}\right)_{\alpha}^{L},\left(\widetilde{C}_{t}\right)_{\alpha}^{U}\right]
$$

Notice that the $\alpha$-level set of $\widetilde{Q}_{t}, \widetilde{r}_{d}, \widetilde{r}_{f}$, and $\widetilde{\sigma}_{\mathrm{Q}}$ are $\left(\widetilde{Q}_{t}\right)_{\alpha}=$ $\left[\left(\widetilde{Q}_{t}\right)_{\alpha}^{L},\left(\widetilde{Q}_{t}\right)_{\alpha}^{U}\right],\left(\widetilde{r}_{d}\right)_{\alpha}=\left[\left(\widetilde{r}_{d}\right)_{\alpha}^{L},\left(\widetilde{r}_{d}\right)_{\alpha}^{U}\right],\left(\widetilde{r}_{f}\right)_{\alpha}=\left[\left(\widetilde{r}_{f}\right)_{\alpha}^{L},\left(\widetilde{r}_{f}\right)_{\alpha}^{U}\right]$, and $\left(\widetilde{\sigma}_{Q}\right)_{\alpha}=\left[\left(\widetilde{\sigma}_{Q}\right)_{\alpha}^{L},\left(\widetilde{\sigma}_{Q}\right)_{\alpha}^{U}\right]$, respectively. Therefore, from (29) and (30), the left endpoint $\left(\widetilde{C}_{t}\right)_{\alpha}^{L}$ and the right-end point $\left(\widetilde{C}_{t}\right)_{\alpha}^{U}$ can be displayed as

$$
\begin{gathered}
\left(\widetilde{C}_{t}\right)_{\alpha}^{L}=\min _{\substack{\left(\widetilde{Q}_{t}\right)_{\alpha}^{L} \leq q \leq\left(\widetilde{Q}_{t}\right)_{\alpha}^{U},\left(\widetilde{r}_{d}\right)_{\alpha}^{L} \leq r_{d} \leq\left(\widetilde{r}_{d}\right)_{\alpha}^{U},\left(\widetilde{r}_{f}\right)_{\alpha}^{L} \leq r_{f} \leq\left(\widetilde{r}_{f}\right)_{\alpha}^{U},\left(\widetilde{\sigma}_{Q}\right)_{\alpha}^{L} \leq \sigma_{Q} \leq\left(\widetilde{\sigma}_{Q}\right)_{\alpha}^{U}}} f\left(q, T-t, K, r_{d}, r_{f}, \sigma_{Q}\right), \\
\left(\widetilde{C}_{t}\right)_{\alpha}^{U}=\max _{\substack{\left(\widetilde{Q}_{t}\right)_{\alpha}^{L} \leq q \leq\left(\widetilde{Q}_{t}\right)_{\alpha}^{U},\left(\widetilde{r}_{d}\right)_{\alpha}^{L} \leq r_{d} \leq\left(\widetilde{r}_{d}\right)_{\alpha}^{U},\left(\widetilde{r}_{f}\right)_{\alpha}^{L} \leq r_{f} \leq\left(\widetilde{r}_{f}\right)_{\alpha}^{U},\left(\widetilde{\sigma}_{Q}\right)_{\alpha}^{L} \leq \sigma_{Q} \leq\left(\widetilde{\sigma}_{Q}\right)_{\alpha}^{U}}} f\left(q, T-t, K, r_{d}, r_{f}, \sigma_{Q}\right) .
\end{gathered}
$$

Moreover, according to the sensitivity analysis (Greek letters) of the G-K formula [18], we have

$$
\begin{gathered}
\frac{\partial f}{\partial q}=e^{-r_{f} t} N\left(d_{1}\right)>0, \\
\frac{\partial f}{\partial r_{d}}=t \cdot K \cdot e^{-r_{d} t} N\left(d_{2}\right)>0, \\
\frac{\partial f}{\partial r_{f}}=-t \cdot q \cdot e^{-r_{f} t} N\left(d_{1}\right)<0, \\
\frac{\partial f}{\partial \sigma_{Q}}=q \cdot e^{-r_{f} t} N^{\prime}\left(d_{1}\right) \cdot \sqrt{t}>0 .
\end{gathered}
$$

This mean $f$ is increasing with respect to $q, r_{d}$, and $\sigma_{\mathrm{Q}}$ and is decreasing with respect to $r_{f}$. Therefore, from (31), we conclude that

$$
\begin{aligned}
& \left(\widetilde{C}_{t}\right)_{\alpha}^{L}=f\left(\left(\widetilde{Q}_{t}\right)_{\alpha}^{L}, T-t, K,\left(\widetilde{r}_{d}\right)_{\alpha}^{L},\left(\widetilde{r}_{f}\right)_{\alpha}^{U},\left(\widetilde{\sigma}_{Q}\right)_{\alpha}^{L}\right), \\
& \left(\widetilde{C}_{t}\right)_{\alpha}^{U}=f\left(\left(\widetilde{Q}_{t}\right)_{\alpha}^{U}, T-t, K,\left(\widetilde{r}_{d}\right)_{\alpha}^{U},\left(\widetilde{r}_{f}\right)_{\alpha}^{L},\left(\widetilde{\sigma}_{\mathrm{Q}}\right)_{\alpha}^{U}\right) .
\end{aligned}
$$

On the other hand, from Proposition 10, the membership function of $\widetilde{C}_{t}$ can also be written as

$$
\mu_{\widetilde{C}_{t}}(c)=\sup _{0 \leq \alpha \leq 1} \alpha \cdot 1_{\left(\widetilde{C}_{t}\right)_{\alpha}}(c) .
$$


Finally, (28), (33), and (34) constitute the fuzzy version of the G-K formula for European call currency option.

Similarly, the conclusions about European put currency option are as follows, through the above discussions.

The original price of European put currency option $P_{t}$ at time $t \in[0, T]$ turns into fuzzy subset $\widetilde{P}_{t} \in \mathscr{F}$ with the membership function under Assumption 1

$$
\begin{aligned}
\mu_{\widetilde{P}_{t}}(p)= & \sup _{\left\{\left(q, r_{d}, r_{f}, \sigma_{Q}\right) \mid p=g\left(q, T-t, K, r_{d}, r_{f}, \sigma_{Q}\right)\right\} \cap \operatorname{Supp}(\widetilde{A})} \\
& \times \min \left\{\mu_{\widetilde{Q}_{t}}(q), \mu_{\widetilde{r}_{d}}\left(r_{d}\right), \mu_{\widetilde{r}_{f}}\left(r_{f}\right), \mu_{\widetilde{\sigma}_{Q}}\left(\sigma_{\mathrm{Q}}\right)\right\},
\end{aligned}
$$

where $\operatorname{Supp}(\widetilde{A})$ is as above. Furthermore, the fuzzy price $\widetilde{P}_{t}$ at time $t \in[0, T]$ is a fuzzy number and the $\alpha$-level set $\left(\widetilde{P}_{t}\right)_{\alpha}$ of $\widetilde{P}_{t}$ is a closed interval

$$
\left(\widetilde{P}_{t}\right)_{\alpha}=\left[\left(\widetilde{P}_{t}\right)_{\alpha}^{L},\left(\widetilde{P}_{t}\right)_{\alpha}^{U}\right]
$$

Moreover, the left endpoint $\left(\widetilde{P}_{t}\right)_{\alpha}^{L}$ and the right endpoint $\left(\widetilde{P}_{t}\right)_{\alpha}^{U}$ can be displayed as

$$
\begin{aligned}
& \left(\widetilde{P}_{t}\right)_{\alpha}^{L}=g\left(\left(\widetilde{Q}_{t}\right)_{\alpha}^{U}, T-t, K,\left(\widetilde{r}_{d}\right)_{\alpha}^{U},\left(\widetilde{r}_{f}\right)_{\alpha}^{L},\left(\widetilde{\sigma}_{Q}\right)_{\alpha}^{L}\right), \\
& \left(\widetilde{P}_{t}\right)_{\alpha}^{U}=g\left(\left(\widetilde{Q}_{t}\right)_{\alpha}^{L}, T-t, K,\left(\widetilde{r}_{d}\right)_{\alpha}^{L},\left(\widetilde{r}_{f}\right)_{\alpha}^{U},\left(\widetilde{\sigma}_{Q}\right)_{\alpha}^{U}\right) .
\end{aligned}
$$

On the other hand, the membership function of $\widetilde{P}_{t}$ can also be written as

$$
\mu_{\widetilde{P}_{t}}(p)=\sup _{0 \leq \alpha \leq 1} \alpha \cdot 1_{\left(\widetilde{P}_{t}\right)_{\alpha}}(p)
$$

Finally, (35), (37), and (38) constitute the fuzzy version of the $\mathrm{G}-\mathrm{K}$ formula for European put currency option.

\section{Defuzzification via Weighting Parameter Identification and Numerical Analysis}

In this section, we defuzzify the fuzzy price for European currency option $\widetilde{C}_{t}\left(\widetilde{P}_{t}\right)$. Then an numerical example is presented. Up to now, it is proved that the fuzzy price for European currency option is a fuzzy number under Assumption 1. For practical purposes, it may be convenient to find a crisp number that synthesizes the fuzzy number $\widetilde{C}_{t}\left(\widetilde{P}_{t}\right)$. This type of problem is known as the "defuzzification procedure" in the literature. Defuzzification is the process to select an appropriate crisp value based on a fuzzy set such that the selected crisp value may represent the fuzzy set in some sense.

Of all the methods of defuzzification, two most popular methods are the center of area (COA) and the mean of maxima (MOM) which require explicit membership function. Now, the membership function of $\widetilde{C}_{t}\left(\widetilde{P}_{t}\right)$ cannot be expressed explicitly; it can be deduced by the decomposition theorem (see (34) or (38)) or the extension principle (see (28) or (35)) only. Since its $\alpha$-level sets of $\widetilde{C}_{t}\left(\widetilde{P}_{t}\right)$ are available (see (33) or (37)), the weighted possibilistic mean value of Fullér and
Majlender [20] about fuzzy number is fited to be the crisp number that we needed (see Definition 9) in the following.

Next, the proposed fuzzy version of the G-K formula (28) is tested with the daily market price data of EUR/USD currency option. To compare with the results in $[16,18]$ conveniently, the market data from [16] are used in Example 18. In the following example, we assumed that the weighting function is $f_{n}(x) \triangleq(1+n) \alpha^{n}$, where $0 \leq \alpha \leq 1$ is the belief degree and $n$ is the belief degree of weighting parameter.

Example 18. A European EUR/USD currency call option is studied on march 16, 2006. For the EUR/USD currency option, the spot exchange rate is 1.215 , the 3 -month volatility is around $9.0 \%$, the domestic 3-month interest rate is around $4.93 \%$, the foreign 3 -month interest rate is around $2.71 \%$, and the strike price is 1.21 with 3-month to expiry. The market price of this currency option is 0.0274 USD. The fuzzy foreign and domestic interest rates, the fuzzy spot exchange rate, and the fuzzy volatility are assumed to triangular fuzzy numbers: $\widetilde{Q}_{t}=(1.2138,1.2150,1.2162), \widetilde{\sigma}_{\mathrm{Q}}=(7.2 \%, 9.0 \%, 10.8 \%)$, $\widetilde{r}_{d}=(4.91 \%, 4.93 \%, 4.95 \%)$, and $\widetilde{r}_{f}=(2.69 \%, 2.71 \%, 2.72 \%)$, respectively.

The fuzzy price $\widetilde{C}_{t}$ of European call currency option can be obtained by (28). Table 1 gives the $\alpha$-level set of the fuzzy price $\widetilde{C}_{t}$ for different belief degrees $\alpha$ and the $f$-weighted possibilistic mean value $\bar{M}_{f_{n}}\left(\widetilde{C}_{t}\right)$ for different belief degrees of weighting parameters $n$, respectively. In fact, if $Q_{t}=1.215$, $r_{d}=4.93 \%, r_{f}=2.71 \%$, and $\sigma_{\mathrm{Q}}=9.0 \%$, then European call currency option price is $0.027872 \$$ by the G-K formula (24). This situation matches the observation $C_{t}=0.027872 \$$ with belief degree 1 .

Remark 19. There are some differences between the $\alpha$-level sets of fuzzy call option price in this paper and those in $[16$, 18], which are shown in Table 1 . The reason is that the division operation of fuzzy numbers in $[16,18]$ is invalid occasionally. Table 1 also shows that $\bar{M}_{f_{n}}\left(\widetilde{C}_{t}\right)$ is the best approximation to the real price when $n=2$.

Next, assuming the currency option prices $C_{t_{1}}, C_{t_{2}}$, $\ldots, C_{t_{N}}$ at $t_{1}, t_{2}, \ldots, t_{N}$ dates are available, how to acquire a more accurate $C_{t_{N+1}}$ at $t_{N+1}$ date is an important question. Based on minimizing the mean square error between the market prices and WPMs, a method of weighting parameter identification is presented as follows.

Frame:

(i) collect the market price data: $C_{t_{1}}, C_{t_{2}}, \ldots, C_{t_{N}}$

(ii) calculate the performance index $J(n)=$ $\sum_{i=1}^{N}\left(\int_{0}^{1}\left(\left(\left(\widetilde{C}_{t_{i}}\right)_{\alpha}^{L}+\left(\widetilde{C}_{t_{i}}\right)_{\alpha}^{U}\right) / 2\right)(1+n) \alpha^{n} \mathrm{~d} \alpha-C_{t_{i}}\right)^{2} ;$

(iii) solve $\min _{0 \leq n \leq 1} J(n)$ and optimal solution $n^{*}$ is obtained and;

(iv) calculate $\bar{M}_{f_{n}}\left(\widetilde{C}_{t_{N+1}}\right)=\int_{0}^{1}\left(\left(\left(\widetilde{C}_{t_{N+1}}\right)_{\alpha}^{L}+\left(\widetilde{C}_{t_{N+1}}\right)_{\alpha}^{U}\right) / 2\right)(1+$ $\left.n^{*}\right) \alpha^{n^{*}} \mathrm{~d} \alpha$, and let $C_{t_{N+1}}=\bar{M}_{f_{n}}\left(\widetilde{C}_{t_{N+1}}\right)$. 
TABLE 1: Fuzzy EUR/USD currency option price.

\begin{tabular}{lcccc}
\hline & $\alpha$-level set of this paper & $\alpha$-level set of paper [16, 18] & \multicolumn{2}{c}{ WPM } \\
$\alpha$ & $\left.\left[\left(\widetilde{C}_{t}\right)_{\alpha}^{L}, \widetilde{C}_{t}\right)_{\alpha}^{U}\right]$ & {$\left[\left(\widetilde{C}_{t}\right)_{\alpha}^{L},\left(\widetilde{C}_{t}\right)_{\alpha}^{U}\right]$} & $n$ & $\bar{M}_{f_{n}}\left(\widetilde{C}_{t}\right)$ \\
\hline 0.0 & {$[0.022898,0.032859]$} & {$[-0.05526,0.11108]$} & 0 & 0.02787 \\
0.1 & {$[0.023394,0.032360]$} & {$[-0.04644,0.10225]$} & 1 & 0.027589 \\
0.2 & {$[0.023890,0.031860]$} & {$[-0.037785,0.093576]$} & 2 & 0.02745 \\
0.3 & {$[0.024386,0.031360]$} & {$[-0.029274,0.085052]$} & 3 & 0.027312 \\
0.4 & {$[0.024883,0.030860]$} & {$[-0.020886,0.076652]$} & 4 & 0.027174 \\
0.5 & {$[0.025379,0.030361]$} & {$[-0.012604,0.068359]$} & 5 & 0.027036 \\
0.6 & {$[0.025876,0.029861]$} & {$[-0.0044076,0.060155]$} & 6 & 0.0269 \\
0.7 & {$[0.026373,0.029362]$} & {$[0.0037199,0.052020]$} & 7 & 0.026763 \\
0.8 & {$[0.026870,0.028862]$} & {$[0.011796,0.043938]$} & 8 & 0.026628 \\
0.9 & {$[0.027367,0.028363]$} & {$[0.019839,0.035892]$} & 9 & 0.026492 \\
1.0 & {$[0.027864,0.027864]$} & {$[0.027864,0.027864]$} & 10 & 0.026358 \\
\hline
\end{tabular}

\section{Conclusions}

In this paper, the Fuzzy version of the Garman-Kohlhagen (FG-K) formula for pricing European currency option via the extension principle is proposed. In the FG-K formula, the interest rate, the spot exchange rate, and the volatility in conventional G-K formula are replaced by fuzzy numbers. So the FG-K formula is able to keep consistent with the real market. We prove that the fuzzy price for European currency option is a fuzzy number. And then the fuzzy price $\widetilde{C}_{t}\left(\widetilde{P}_{t}\right)$ is defuzzified by the weighted possibilistic mean value. The example shows that the fuzzy price in this paper is more accurate than the ones in $[16,18]$ and the fuzzy prices in $[16$, 18 ] are just approximations to our fuzzy price for European currency option. In addition, the example indicates that the WPM value has different approximation effects to real market price by taking different values of weighting parameter in the weighting function. So an identification method is presented. And the optimal parameter is obtained if we have already known some market prices for European currency option. The method in this paper can be extended to other option pricing. How to find out different kinds of weighting function in defuzzification requires a further study.

\section{Acknowledgments}

This work was supported by 863 Program (Grant no. 2007AA02Z208), 973 Program (Grant no. 2007CB714304), and the National Natural Science Foundation of China (Grants nos. 10871033 and 11171050).

\section{References}

[1] M. B. Garman and S. W. Kohlhagen, "Foreign currency option values," Journal of International Money and Finance, vol. 2, no. 3, pp. 231-237, 1983.

[2] F. Black and M. Scholes, "The pricing of options and corporate liabilities," Journal of Political Economics, vol. 81, no. 3, pp. 637659, 1973.

[3] M. Chesney and L. Scott, "Pricing european currency options: a comparision of the modified black-scholes model and a random variance model," Journal of Financial and Quantitative Analysis, vol. 24, no. 3, pp. 267-284, 1989.

[4] K. Amin and R. Jarrow, "Pricing foreign currency options under stochastic interest rates," Journal of International Money and Finance, vol. 10, no. 3, pp. 310-329, 1991.

[5] S. Heston, "A closed-form solution for options with stochastic volatility with applications to bond and currency options," Review of Financial Studies, vol. 6, no. 2, pp. 327-344, 1993.

[6] D. Bates, "Jumps and stochastic volatility: exchange rate processes implicit in deutsche mark options," Review of Financial Studies, vol. 9, no. 1, pp. 69-107, 1996.

[7] G. Sarwar and T. Krehbiel, "Empirical performance of alternative pricing models of currency options," The Journal of Futures Markets, vol. 20, no. 3, pp. 265-291, 2000.

[8] P. Carr and L. R. Wu, "Stochastic skew in currency options," Journal of Financial Economics, vol. 86, no. 1, pp. 213-247, 2007.

[9] L. A. Zadeh, "Fuzzy sets," Information and Computation, vol. 8, pp. 338-353, 1965.

[10] Y. Yoshida, "The valuation of European options in uncertain environment," European Journal of Operational Research, vol. 145, no. 1, pp. 221-229, 2003.

[11] Y. Yoshida, "A discrete-time model of American put option in an uncertain environment," European Journal of Operational Research, vol. 151, no. 1, pp. 153-166, 2003.

[12] S. Muzzioli and C. Torricelli, "A multiperiod binomial model for pricing options in a vague world," Journal of Economic Dynamics \& Control, vol. 28, no. 5, pp. 861-887, 2004.

[13] H. C. Wu, "Using fuzzy sets theory and Black-Scholes formula to generate pricing boundaries of European options," Applied Mathematics and Computation, vol. 185, no. 1, pp. 136-146, 2007.

[14] W. D. Xu, C. F. Wu, W. J. Xu, and H. Y. Li, "A jump-diffusion model for option pricing under fuzzy environments," Insurance: Mathematics \& Economics, vol. 44, no. 3, pp. 337-344, 2009.

[15] L. H. Zhang, W. G. Zhang, W. J. Xu, and W. L. Xiao, "The double exponential jump diffusion model for pricing European options under fuzzy environments," Economic Modelling, vol. 29, no. 3, pp. 780-786, 2012.

[16] F. Y. Liu, "Pricing currency options based on fuzzy techniques," European Journal of Operational Research, vol. 193, no. 2, pp. 530-540, 2009.

[17] H. C. Wu, "European option pricing under fuzzy environments," International Journal of Intelligent Systems, vol. 20, no. 1, pp. 89-102, 2005. 
[18] W. J. Xu, W. D. Xu, H. Y. Li, and W. G. Zhang, "A study of Greek letters of currency option under uncertainty environments," Mathematical and Computer Modelling, vol. 51, no. 5-6, pp. 670681, 2010.

[19] M. L. Guerra, L. Sorini, and L. Stefanini, "Option price sensitivities through fuzzy numbers," Computers \& Mathematics with Applications, vol. 61, no. 3, pp. 515-526, 2011.

[20] R. Fullér and P. Majlender, "On weighted possibilistic mean and variance of fuzzy numbers," Fuzzy Sets and Systems, vol. 136, no. 3, pp. 363-374, 2003.

[21] Y. Chalco-Cano, H. Román-Flores, M. Rojas-Medar, O. R. Saavedra, and M. D. Jiménez-Gamero, "The extension principle and a decomposition of fuzzy sets," Information Sciences, vol. 177, no. 23, pp. 5394-5403, 2007.

[22] D. P. Bertsekas, A. Nedić, and A. E. Ozdaglar, Convex Analysis and Optimization, Athena Scientific, Belmont, Mass, USA, 2003.

[23] L. A. Zadeh, "The concept of a linguistic variable and its application to approximate reasoning-I," Information Sciences, vol. 8, no. 3, pp. 199-249, 1975.

[24] L. A. Zadeh, "The concept of a linguistic variable and its application to approximate reasoning-II," Information Sciences, vol. 8, no. 3, pp. 301-357, 1975.

[25] L. A. Zadeh, "The concept of a linguistic variableand its application to approximate reasoning-III," Information Sciences, vol. 9, no. 1, pp. 43-80, 1975.

[26] T. M. Apostol, Mathematical Analysis, Addison-Wesley, Reading, Mass, USA, 2nd edition, 1974.

[27] M. Musiela and M. Rutkowski, Martingale Methods in Financial Modelling, vol. 36 of Stochastic Modelling and Applied Probability, Springer, Berlin, Germany, 2nd edition, 2005. 


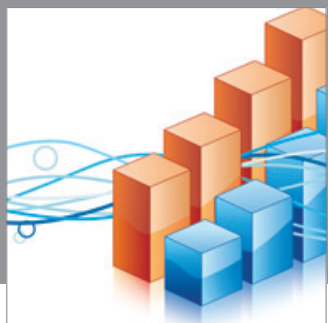

Advances in

Operations Research

mansans

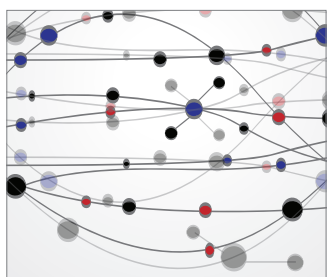

The Scientific World Journal
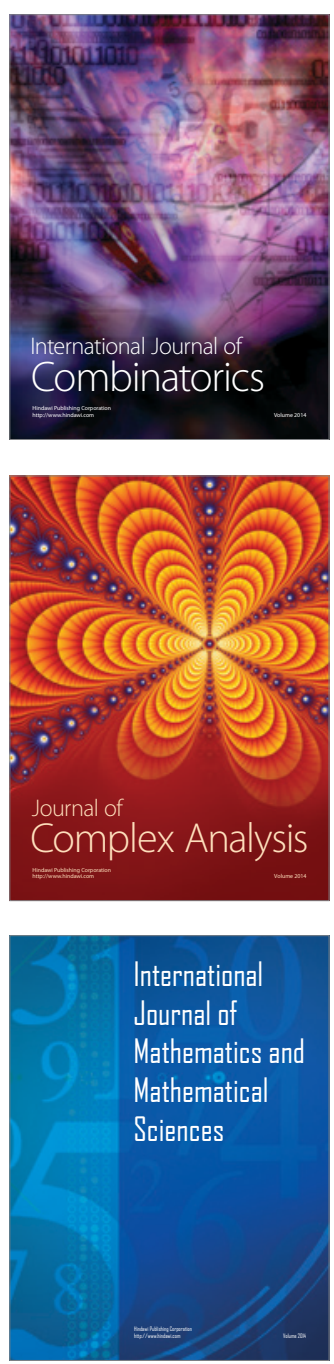
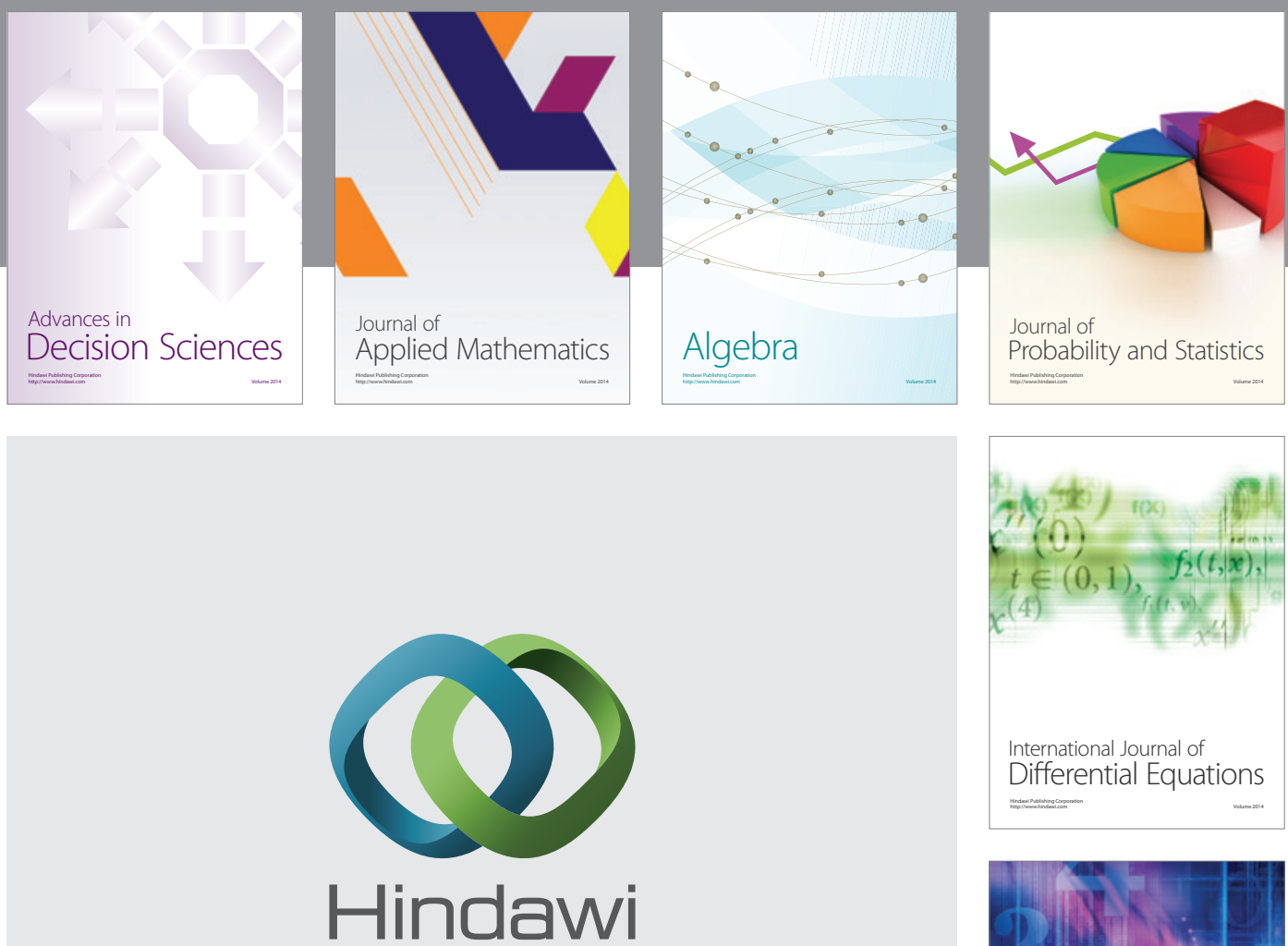

Submit your manuscripts at http://www.hindawi.com
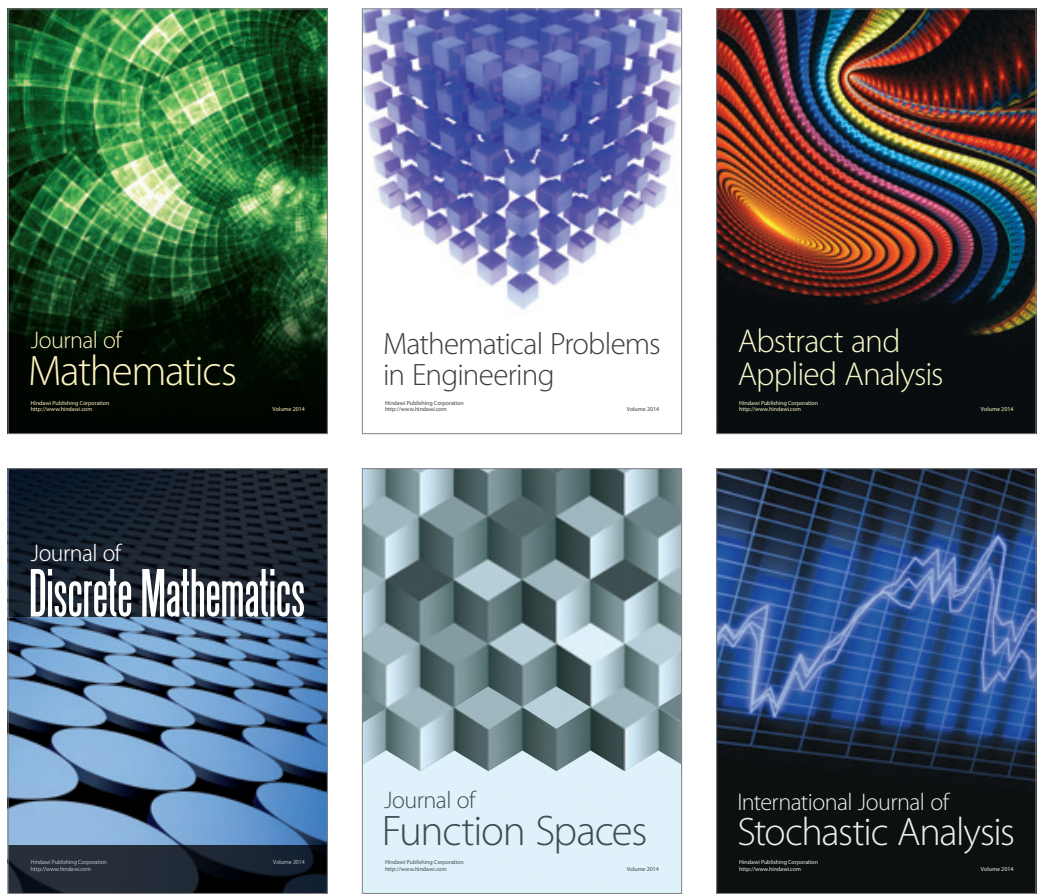

Journal of

Function Spaces

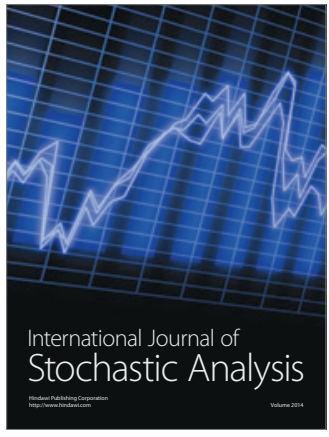

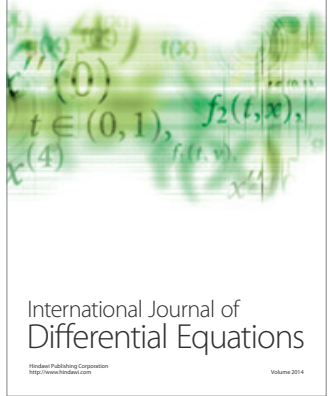
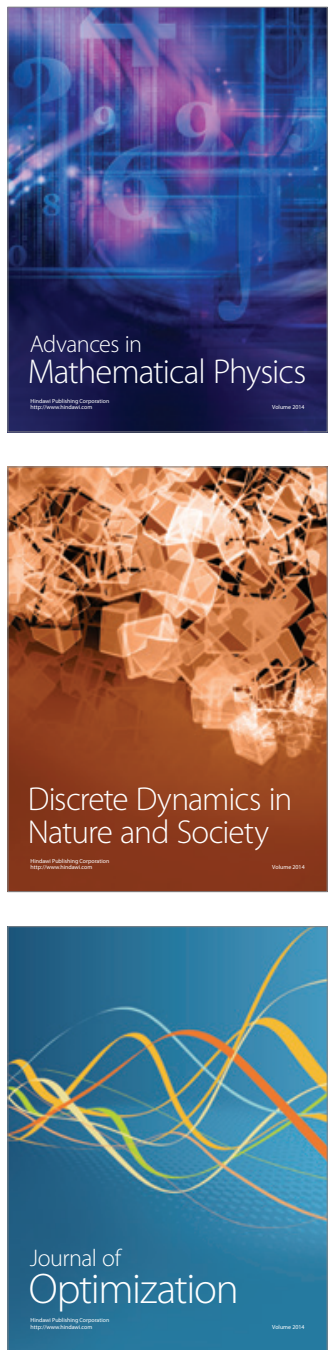